\title{
Worksite Health Program Promoting Changes in Eating Behavior and Health Attitudes
}

\author{
Stefanie Mache, MSc, $\mathrm{MHA}^{1}$ \\ Sarah Jensen, $\mathrm{BA}^{2}$ \\ Reimo Jahn, $\mathrm{MSc}^{3}$ \\ Mirko Steudtner, BSc ${ }^{4}$ \\ Elke Ochsmann, $\mathrm{MD}^{4}$ \\ Geraldine Preuß, $\mathrm{MD}^{5}$
}

Background. The aim of the present study was to evaluate the effectiveness of a worksite multicomponent health promotion intervention on eating behavior and attitudes, changes in body weight, and readiness to make eating behavior changes among workers over a 12-month intervention period. Method. A total of 3,095 workers of a logistic company participated in a quasiexperimental comparison group study design. The intervention group received a multicomponent health training. Two of the main elements of the multicomponent intervention were physical exercise training and nutrition counseling/training. During the pilot year, participants completed a survey at baseline and again after 12 months to assess physical activity-, health-, and diet-related factors. Results. Results showed that participants' body weight did not significantly decrease in the intervention group. Mean weight loss in the intervention groups was $0.5 \mathrm{~kg}$ (body mass index $=0.1 \mathrm{~kg} / \mathrm{m}^{2}$ ). Eating behaviors in the intervention group improved more than in the comparison group. Some positive intervention effects were observed for the cognitive factors (e.g., changes in eating attitudes). Baseline readiness to change eating behavior was significantly improved over time. Conclusions. We demonstrated initial results of a long-term multicomponent worksite health promotion program with regard to changes in body weight, eating behavior, and attitudes. This evaluation of a 12-month pilot study suggests that a worksite health promotion program may lead to improvements

Health Promotion Practice

November 2015 Vol. 16, No. (6) 826-836

DOI: $10.1177 / 1524839915596310$

(C) 2015 Society for Public Health Education in nutritional health behaviors for a number of workers. An investigation of long-term effects of this multicomponent intervention is strongly recommended.

Keywords: dietary change; health promotion; weight reduction; workplace

\section{INTRODUCTION}

The worldwide increasing prevalence of overweight and obesity is a cause for concern as the overweightrelated morbidity, mortality, and health care costs concurrently increase (Verweij, Coffeng, van Mechelen, \& Proper, 2011). According to the Robert Koch Institute (the central federal institution responsible for disease control and prevention in Germany), more than $30 \%$ of German workers are currently overweight (i.e., a body

\footnotetext{
${ }^{1}$ University Medical Center Hamburg-Eppendorf, Hamburg, Germany

${ }^{2}$ Bremen International Graduate School of Social Sciences, Bremen, Germany

${ }^{3}$ Helmut Schmidt University, Hamburg, Germany

${ }^{4}$ University of Applied Sciences Zwickau, Zwickau, Germany

${ }^{5}$ Charité Universitätsmedizin Berlin-Humboldt University of Berlin-Free University of Berlin, Germany
}

Authors' Note: SM, GP, and EO designed the study. SM, SJ, RJ, $M S$, EO, and GP performed the investigation, interpreted the data, and contributed substantially to its revision. SM and SJ analyzed the data. SM wrote the article. Address correspondence to Stefanie Mache, Institute for Occupational and Maritime Medicine (ZfAM), University Medical Center HamburgEppendorf, Seewartenstrasse 10, 20459 Hamburg, Germany; e-mail: s.mache@uke.de. 
mass index [BMI] of $25-29 \mathrm{~kg} / \mathrm{m}^{2}$ ) and at least $20 \%$ are obese (BMI $\geq 30 \mathrm{~kg} / \mathrm{m}^{2}$; Mensink et al., 2013). Cardiovascular disease, type 2 diabetes, musculoskeletal disorders, and a lower quality of life cause much of the morbidity and years of life lost associated with increasing levels of obesity (Berghoefer, Pischon, \& Reinhold, 2008; Graf, Ferrari, \& Eiser, 2013). In addition, it has been demonstrated that overweight and obesity are related to increased absenteeism rates and productivity loss (Van Duijvenbode, Hoozemans, Van Poppel, \& Proper, 2009). Thus, obesity and overweight cause economic costs (Berghoefer et al., 2008; Chapman, 2003).

\section{Worksite Health Promotion}

A focus on primary prevention (e.g., improving physical activity and dietary behavior or weight loss) is important, as population-based interventions of weight reduction may prove to be more effective than individual management of overweight issues (Deusinger, 2012; Verweij et al., 2011). Similarly, an increasing number of studies have been performed to prevent weight gain by targeting physical activity and dietary behavior (Verweij et al., 2011). In addition, growing attention is given to the effects of worksite health promotion programs (Verweij et al., 2011). As mentioned by Hutchinson and Wilson (2011), the workplace has been reflected as an adequate intervention site. Reasons include (1) the amount of time employees spend at work, (2) access to groups of population that are difficult to reach for health promotion, and (3) the chance to use peer networks, employer support, as well as incentives.

Several systematic reviews have been conducted that found significant effects on weight outcomes, physical activity, dietary behavior, as well as a combination of physical activity and dietary behavior (Maes et al., 2012; Matson-Koffman, Brownstein, Neiner, \& Greaney, 2005; Vuillemin et al., 2011). Effective interventions to prevent such burden of disease may have economic benefits besides improvement of health and quality of life (Schröer, Haupt, \& Pieper, 2014; van Dongen et al., 2012). Consequently, improvements in health may lead to reduced sick leaves and/or absenteeism and, thus, increased productivity (Jensen, 2011; Kuoppala, Lamminpaa, \& Husman, 2008; Odeen et al., 2013).

\section{Theoretical Background of the Intervention Design}

This worksite health promotion intervention was designed with regard to the modified ecological framework (Stokols, 1992). Based on this model, the workplace is a system in which environmental factors can be changed in a way that motivate employees to modify their health behavior (Jacobson, Yenney, \& Bisgard, 1990). Relevant worksite factors for health behavior change are for example social norms, leadership principles, and company morale. At the individual level, the intervention was based (1) on the social learning theory, which emphasizes self-efficacy and the role of support in behavior change (Bandura, 1963), and (2) on the transtheoretical model of health behavior change (Prochaska \& Velicer, 1997). The processes of change dimension of the transtheoretical model include cognitive, affective, evaluative, and behavioral strategies that an employee can use to change the eating and or physical activity health behavior (Prochaska \& Marcus, 1994).

\section{Study Aim}

The aim of this study is to evaluate the effectiveness of a multicomponent worksite intervention program in promoting dietary changes, including shifts in stages of readiness to change dietary behavior, eating-related attitudes, as well as other behavioral health determinants among workers of a German logistics company. Moreover, associations between sociodemographic data (e.g., body weight, gender) and behavioral as well as cognitive outcomes are of interest.

We hypothesize that between baseline (to) and the end of the intervention (follow-up, t2):

1. There will be a significant reduction in "body weight"/"BMI."

2. Significant differences in secondary outcomes "eating habits/food consumption," "behavioral eating attitudes," and "stages of readiness to change dietary behavior" between the intervention and the comparison group will be identified.

\section{METHOD}

\section{Study Design}

The effectiveness of the worksite health intervention has been evaluated in a quasi-experimental comparison group study. Participants who gave informed consent were measured at baseline (t0), as well as 6 months (t1, process evaluation), and 12-months of follow-up (t2; see Supplementary Figure 1, available online at http://hpp.sagepub.com/supplemental).

\section{Ethics}

The ethical aspects were in full agreement with the Helsinki Declaration. Rules and regulations of the research ethics board are fulfilled. 


\section{Outcome Assessments}

Outcome assessments occur at baseline (t0), at 6 months (t1), and at 12 months (t2). Results of the process evaluation ( $\mathrm{t} 1$ measurement) are reported elsewhere. The assessment focused on several outcomes mainly on nutrition and physical activity behavior changes. In this article, we present the results related to nutrition outcomes. Results on physical activity behavior are reported in a further separate publication.

Primary results of worksite health intervention related to nutrition outcomes have been evaluated on the following types of outcome measures:

1. Changes in weight and BMI

2. Changes in eating behavior, eating attitudes, and stages of readiness to change dietary practices

\section{Participants}

A total of 1,573 workers of a German logistics company were invited to participate between January 2013 and December 2013 in a multicomponent health promotion training (intervention group) as an employee benefit. In addition, a comparison group of 1,522 employees comparable to the intervention group in sociodemographic and work-related variables (e.g., gender, age, job description, location, etc.) were included. Employees of the comparison group work in a different but comparable workplace. Therefore, the potential for employees in the comparison group to have attended intervention program activities is very low and further contamination effects are minimal (e.g., communication about the health promotion program with members of the intervention group). All workers were assessed in the same time frame, informed about the health promotion training in their worksite, and asked to enroll. Worksites promoted the program with, that is, posters, flyers, kickoff meetings.

In total, 890 participants of the intervention group (response rate $=58 \%$ ) and 859 of the comparison group completed the baseline assessment (response rate = $56 \%$ ). At follow-up, 793 participants of the intervention group and 697 employees of the comparison group filled out the questionnaire (response rates $=50 \%$ vs. $46 \%$ ). Survey data at t0 and t2 were subsequently matched. Matched sample participants represent the workers identified by age, sex, and height with a completed assessment at baseline and follow-up. In addition, we used self-generated identification codes based on initials (e.g., mother's maiden name, etc.) to match questionnaires. In all, 377 employees (matched intervention group) and 298 (matched comparison group) answered both questionnaires (at baseline and followup; see Figure 1).

Individual randomization was not possible due to organizational regulations. Groups of workers have been assigned to either the intervention or comparison group.

\section{Intervention}

Participants in the intervention group received a 12-month health promotion intervention.

The training sessions took approximately 30 to 60 minutes every week/2 weeks and were held, for example, in a separate room at the worksite in a group setting of 15 to 20 participants or as individual "one-to-one," activity-related coaching session. The same sessions were offered multiple times. Employees participated during paid working hours; the timetable was adapted to working hours as much as possible (e.g., before working hours, around lunchtime, and after working hours).

Several qualified and certified trainers (training certificate: German ABC License) communicated educational information and advice on healthful eating and physical activity and performed other health promotion activities (e.g., the trainer offered personalized nutrition counseling and cooking lessons over the time period).

\section{Activities for Improving Nutritional Habit}

Improving nutritional habits was one of the aims of the health promotion program. Therefore, trainers discussed main nutritional information (e.g., fluid intake, protein intake, energy intake).

For convincing employees to change their nutritional habits, trainers used motivational interviewing techniques. Nutritional counseling also included individual goal setting and ways to reinforce self-efficacy. Trainer also demonstrated possible problems of implementing the goal in everyday life, to find solutions for them.

In addition, free fruit and vegetables were provided during training and physical exercise training was included in the workplace sessions.

\section{Activities for Improving Physical Activity}

Physical activity training focused on general body strength training and included exercises such as back extension, shoulders, and arms, particularly with regard to the occupational exposure. In the beginning of the physical activity training, a warm-up (about 5 minutes 
of mobilization exercises) was performed followed by strength exercises, which were implemented in circuit form. The exercises were conducted with repetitions until muscular exhaustion. This circle lasted about 30 minutes. Moreover, the trainers talked about the relevance of health-enhancing physical activity. The trainers also discussed possible arising problems, talked about their baseline activity, and set individual goals concerning physical activity.

\section{One-on-One Coaching Sessions}

The individual coaching sessions were performed as a combination of nutrition and physical activity (one-to-one personal development service providing the knowledge, motivation, tools needed for change physical activity, and/or nutrition behavior), tailored dietary and physical activity recommendations, and motivational and cognitive behavioral interventions such as increasing self-efficacy, problem solving, and goal setting. Eating more servings of fruits and vegetables, increasing physical activity per week, and reducing work stress were all emphasized as healthy behaviors. No attendance requirements were placed on the intervention group. The coaching lasted approximately 30 to 45 minutes per session. Frequency of coaching was at least twice per month on request. All the trainers had a standardized training protocol.

\section{Measurements}

The primary outcome "weight" was measured as a self-reported value. Weight status has been evaluated in three categories based on BMI; 1 = normal weight, 2 = overweight, 3 = obese. BMI is calculated by dividing body weight in kilograms by the squared body height in meters and has been measured from self-reported height and weight at baseline (t0) and follow-up (t2).

\section{Eating Behavior and Dietary Intake}

We used the FEG (Fragebogen zur Erfassung des Gesundheitsverhaltens [Questionnaire for the Assessment of Health Behavior]) developed by Dlugosch (1992) to measure secondary outcomes of eating attitudes and behaviors. The survey includes 85 items asking for health behavior and attitudes (eating, physical activity, smoking, etc.). We used the scales asking for assessing changes in nutrition behavior and dietary intake. Part of the FEG is, for example, a short food questionnaire, consisting of six questions on intake frequency of fruits, vegetables, sweets (chocolate, cake, etc.), fast food, meat products, and soft drinks (e.g., cola/lemonade) by using categorical response options
$(1$ = several times a day, $2=$ daily, $3=$ several times $a$ week, $4=$ seldom, $5=$ never ) for each category. The survey has been previously validated toward reliability, validity, and objectivity by Dlugosch (1992).

\section{Stage of Readiness to Change Eating Behavior}

The assessment of the "readiness to change eating behavior" stage represents ordered categories of motivational readiness to change (precontemplation, contemplation, preparation, action, maintenance) and was based on the recommendations of Prochaska et al. (2005). For practical reasons, the stages of readiness to change were collapsed into four categorical variables. Response options for this question were categorical: "I do not want to change anything/I have no plans to start" (precontemplation), "considering a change" (contemplation), "making plans to change" (preparation), and "I started doing this" (action, maintenance; Prochaska et al., 2005).

\section{Eating-Related Attitudes}

Eating-related attitudes and behaviors were measured by the EGE (Einstellung zu gesunder Ernährung [Questionnaire for the Assessment of Eating-and Weight-Related Attitudes and Behaviors]; Diehl \& Staufenbiel, 1999). We included two scales for measurement. One scale contains eight items on healthy eating attitudes, for example, "I am very conscious of how much fat is in the food I eat"; the other scale includes six items on healthy eating behavior, for example, "I eat lots of vegetables." Items can be rated on a on a 4-point Likert-type scale $(1=$ strongly disagree, 2 = disagree, 3 = agree, $4=$ strongly agree . Psychometric qualities were acceptable at all measurements (e.g., range Cronbach's $\alpha=.65-.71$; Diehl \& Staufenbiel, 1999).

\section{Confounders}

At baseline, data on potential confounders were assessed, including age, gender, and marital status (defined by the following categories: married/partnership/single/divorced/widowed).

\section{Statistical Analyses}

Descriptive statistics were used to characterize baseline demographics, behavioral, attitude, and weight loss outcomes. Chi-square and $t$ tests determined significant differences and associations of sociodemographics, eating behaviors, and attitudes toward nutrition. Multivariate logistic regression models 
TABLE 1

Selected Demographic Characteristics of Participants (Baseline) and 12-month Follow-Up Matched Participants

\begin{tabular}{|c|c|c|c|c|}
\hline Variables & $\begin{array}{l}\text { Participants } \\
\text { (Intervention } \\
\text { Group, } \mathrm{n}=890)^{a}\end{array}$ & $\begin{array}{l}\text { Participants } \\
\text { (Control Group, } \\
\mathrm{n}=859 \text { ) } a\end{array}$ & $\begin{array}{l}\text { Matched Sample } \\
\text { Participants (Intervention } \\
\text { Group, } \mathrm{n}=377)^{b}\end{array}$ & $\begin{array}{l}\text { Matched Sample } \\
\text { Participants (Control } \\
\text { Group, } \mathrm{n}=298 \text { ) }\end{array}$ \\
\hline \multicolumn{5}{|c|}{ Age-group (years, \%) ${ }^{\mathrm{C}}$} \\
\hline 21-30 & 8.0 & 6.1 & 7.3 & 5.7 \\
\hline $31-40$ & 17.3 & 16.0 & 18.5 & 12.8 \\
\hline $41-50$ & 43.5 & 41.7 & 38.6 & 46.3 \\
\hline $51-60$ & 29.9 & 34.8 & 34.8 & 34.2 \\
\hline$>60$ & 1.3 & 1.4 & 0.8 & 1.0 \\
\hline \multicolumn{5}{|l|}{ Sex $(\%)$} \\
\hline Male & 44.4 & 31.7 & 42.2 & 27.5 \\
\hline Female & 55.6 & 69.3 & 57.8 & 70.1 \\
\hline \multicolumn{5}{|c|}{ BMI $\left(\mathrm{kg} / \mathrm{m}^{2}\right)$} \\
\hline$M(S D)$ & $25.9(3.6)$ & $25.1(3.5)$ & $25.3(3.9)$ & $25.2(3.9)$ \\
\hline
\end{tabular}

NOTE: $\mathrm{BMI}=$ body mass index.

${ }^{a}$ Workers completed a baseline questionnaire. ${ }^{b}$ Matched sample participants represent the workers identified by self-generated identification codes, age, sex, and height with a completed assessment at baseline and follow-up. ${ }^{\mathrm{C}}$ Amount of missing values are not described; thus percentages across columns do not add up to $100 \%$.

were performed to determine predictors of significant weight loss. In addition, we performed linear mixed effect models with the outcome measures as the dependent variable, group (intervention vs. comparison group) as independent variable and time of follow-up measurements as fixed factor, while adjusting for the baseline levels of the outcome measure. A $p<.05$ was considered to indicate statistical significance. All statistical analyses were performed using SPSS (Version 21).

\section{RESULTS}

\section{Baseline Characteristics of the Study Participants}

Table 1 presents the characteristics of the participants (intervention and comparison group). Chi-square tests show no significant differences between the intervention group and comparison group characteristics at baseline with regard to relevant sociodemographic factors (e.g., age; $p>$.05).

The full intervention group consisted mainly of older workers (up to 30 years: 8\%, 31-40 years: $17.3 \%$, 41-50 years: $43.5 \%$, and 51-60 years: $29.9 \%$ ). The mean age of the study population was 44 years $(S D=10.26)$. Participants consisted of $45 \%$ female workers and $55 \%$ male workers. The majority of the entire intervention group had a normal body weight: mean BMI was 25.9
$(S D=3.6)$; mean BMI of the full comparison group was $25.6(S D=3.4)$.

At baseline, 55\% of the whole intervention participants had a normal weight status (comparison group: $52 \%$ ), 34\% were overweight (comparison group: $35 \%$ ), $12 \%$ were obese (comparison group: 11\%). We found no significant differences between intervention and comparison group $(p>.05)$.

\section{Weight Loss: Changes in Body Weight and Body Mass Index}

The matched intervention group did not experience statistically significant changes in body weight (from to to t2). Mean weight loss in the intervention groups was $M=0.5 \mathrm{~kg}, S D=0.4\left(\mathrm{BMI}=0.1 \mathrm{~kg} / \mathrm{m}^{2} ;\right.$ men: $M=0.6 \mathrm{~kg}$, $S D=0.2 \mathrm{~kg}$; women: $0.4 \mathrm{~kg}, S D=0.3 \mathrm{~kg}$ ). The comparison group did also not significantly change body weight between baseline and follow-up.

After 12 months, $7 \%$ of the intervention group $(n=26)$ reported having lost at least $5 \%$ of their body weight, and an additional 3\% $(n=11)$ had lost at least $10 \%$. No significant differences (interaction between group and time) were seen in change in weight and BMI in both sexes $(p>.05)$.

At 12-month follow-up, mean BMI of the whole intervention group was $25.3(S D=3.9)$. The comparison group showed a mean of $M=25.5, S D=4.3$. Differences 
in $\mathrm{BMI}$ between $\mathrm{t} 0$ and $\mathrm{t} 2$ were not significantly different (intervention group: $p=.64$; comparison group: $p=.93$; see Supplementary Figure 2, available online at http:// hpp.sagepub.com/supplemental).

\section{Changes in Dietary Intake, Eating Behavior, and Specific Eating Attitudes}

We evaluated changes in dietary intake, eating behaviors, and eating attitudes between baseline and follow-up. Table 2 shows changes (means and standard deviations at baseline and follow-up measurements) for the targeted dietary intake and eating behaviors.

\section{Dietary Intake and Eating Behavior}

At the follow-up, more participants of the intervention group ate any servings of vegetables daily than they did at baseline (31.6\% vs. $45.6 \%, p=.01$; Table 2 ). The data also showed an overall trend of an increased frequency of fruit consumption between baseline and follow-up ( $p=.03$ ). There was a shift in consumption of fruit per day from $45.1 \%$ at baseline to $55.7 \%$ at follow-up. After 12 months, the intervention group showed a larger reduction in fast-food and sweets intake than those in the comparison group, and significant group-by-time interactions were also evident ( $p=.001$; see Table 2$)$.

Female participants eat vegetables and fruits significantly more frequently than their male colleagues ( $p=.01$, at baseline and follow-up). In contrast, male workers eat meat and fast food significantly more frequently than female workers (meat: male: $p=.01$; fast food: $p=.001$, at baseline and follow-up, respectively). No significant gender difference has been found with regard to consumption of sweets $(p>.05)$.

As for food group intake, the male intervention group significantly reduced intakes of fast food and meat $(p=.02)$ and increased intake of vegetables $(p=$ .03 ) and fruits $(p=.04, p=.03$, for group $\times$ time interaction). The female intervention group also significantly reduced intake of fast food and sweets at 12 months ( $p$ $=.02$ ). However, intake of vegetables and fruits did not significantly increase for women $(p>.05)$.

Female and male intervention group did not significantly reduce their soft drink consumption $(p>.05)$.

The next analysis look at changes in weight loss at $\mathrm{t} 2$, controlling for baseline factors (gender, age, etc.).

Linear mixed models showed that fast-food meals and soft drinks were both significantly associated with higher BMIs among men and women, respectively ( $p<$ .05). Greater daily servings of fruit and vegetables were associated with lower BMI among both genders, although this trend was statistically significant only among women $(p<.05)$.

\section{Attitudes to Healthy Eating}

Attitudes to healthy eating were similar in the intervention group and comparison group at baseline. As illustrated in Table 3 and in the Supplementary Table (available online at http://hpp.sagepub.com/supplemental), few significant differences and improvements in eating attitudes between baseline (t0) and follow-up (t2; intervention group) were found. Only one significant group $\times$ time interaction for "taking more time for my meals" could be found (Table 3).

\section{Stage of Readiness to Change for Healthy Eating}

Participants of the intervention group progressed between baseline and follow-up in stages of readiness to change eating behavior ( $p=.001$, see Table 4). Significant differences were found between the intervention and comparison group ( $p=.04$ for group $\times$ time interaction).

Because of the changes that were seen in the intervention group, changes in the proportion of the participants at each stage were evaluated and the relationship between stage change examined: 138 (39\%) of the participants (intervention group) exhibited an increase in readiness to change their eating behavior.

A total of 40 participants $(11 \%)$, among those who were in the precontemplation/contemplation/preparation stage at the baseline, switched to the action/maintenance stage after 12 months.

A total of 200 participants maintained the precontemplation/contemplation/preparation stage. Only nine participants among the participants, who were in the action/maintenance stage at the baseline, went back a stage to the precontemplation/contemplation/preparation stage.

No significant gender differences were analyzed ( $p=.16$ ): Both male and female workers of the intervention group showed significant differences in readiness to change between t0 and $\mathrm{t} 2$ ( $p=.001$; see Table 4$)$. At baseline, $29.3 \%$ of men and $25.6 \%$ of women were in the preparation stage. However, the proportion at this stage increased to $38.6 \%$ in men and $43.8 \%$ in women, and the participants in the action or maintenance stages increased from $7.5 \%$ to $14.3 \%$ in men and from $8.1 \%$ to $11.3 \%$ at 12 months $(p<.05)$.

\section{DISCUSSION}

The study evaluates a 12-month worksite health promotion program. Two of the main elements of the 
TABLE 2

Selected Characteristics of Dietary Intake (Frequency of Consumption) of the Matched Sample Participants at Baseline and 12-month Follow-Up

\begin{tabular}{|c|c|c|c|c|c|c|c|}
\hline $\begin{array}{l}\text { How Often do You } \\
\text { Eat or Drink . . .? }\end{array}$ & $\begin{array}{c}\% \text { at Baseline } \\
\text { (Intervention } \\
\text { Group, } \mathrm{n}=377 \text { ) }\end{array}$ & $\begin{array}{l}\% \text { at Follow-Up } \\
\text { (Intervention } \\
\text { Group, } \mathrm{n}=377 \text { ) }\end{array}$ & $\mathrm{p}$ & $\begin{array}{c}\% \text { at Baseline } \\
\text { (Control Group, } \\
\mathrm{n}=298)\end{array}$ & $\begin{array}{c}\% \text { at Follow-Up } \\
\text { (Control Group } \\
\mathrm{n}=298)\end{array}$ & $\mathrm{p}$ & $\begin{array}{c}\text { Interaction } \\
\text { (Group } \times \\
\text { Time) }\end{array}$ \\
\hline \multicolumn{8}{|l|}{ Vegetables } \\
\hline Several time a day & 3.0 & 6.9 & \multirow[t]{5}{*}{.01} & 6.5 & 7.4 & \multirow[t]{5}{*}{.17} & \multirow[t]{5}{*}{.02} \\
\hline Daily & 28.6 & 38.7 & & 31.2 & 29.2 & & \\
\hline $\begin{array}{l}\text { Several times a } \\
\text { week }\end{array}$ & 50.0 & 44.6 & & 46.8 & 47.0 & & \\
\hline Less often & 10.8 & 8.5 & & 15.6 & 14.8 & & \\
\hline Never & 0 & 0 & & 0 & 0 & & \\
\hline \multicolumn{8}{|l|}{ Fruits } \\
\hline Several time a day & 8.6 & 14.1 & \multirow[t]{5}{*}{.03} & 11.8 & 11.4 & \multirow[t]{5}{*}{.80} & \multirow[t]{5}{*}{.04} \\
\hline Daily & 36.5 & 41.6 & & 42.4 & 41.6 & & \\
\hline $\begin{array}{l}\text { Several times a } \\
\text { week }\end{array}$ & 26.8 & 28.1 & & 27.1 & 27.9 & & \\
\hline Less often & 20.0 & 14.6 & & 17.6 & 18.1 & & \\
\hline Never & 1.4 & 1.1 & & 1.1 & 0.3 & & \\
\hline \multicolumn{8}{|l|}{ Sweets } \\
\hline Several time a day & 4.9 & 5.3 & \multirow[t]{5}{*}{.001} & 3.8 & 3.4 & \multirow[t]{5}{*}{.18} & \multirow[t]{5}{*}{.003} \\
\hline Daily & 22.4 & 20.7 & & 25.9 & 22.5 & & \\
\hline $\begin{array}{l}\text { Several times a } \\
\text { week }\end{array}$ & 38.9 & 43.0 & & 41.8 & 47.0 & & \\
\hline Less often & 26.2 & 27.9 & & 27.8 & 25.2 & & \\
\hline Never & 0.8 & 1.1 & & 0.8 & 0.3 & & \\
\hline \multicolumn{8}{|l|}{ Meat } \\
\hline Several time a day & 8.6 & 5.8 & \multirow[t]{5}{*}{.001} & 6.8 & 7.4 & \multirow[t]{5}{*}{.08} & \multirow[t]{5}{*}{.01} \\
\hline Daily & 37.0 & 44.3 & & 45.6 & 37.2 & & \\
\hline $\begin{array}{l}\text { Several times a } \\
\text { week }\end{array}$ & 39.5 & 35.5 & & 35.0 & 41.6 & & \\
\hline Less often & 6.8 & 12.7 & & 10.6 & 12.1 & & \\
\hline Never & 0.8 & 1.1 & & 0.8 & 0.7 & & \\
\hline \multicolumn{8}{|l|}{ Fast food } \\
\hline Several time a day & 0 & 0 & \multirow[t]{5}{*}{.001} & 0 & 0 & \multirow[t]{5}{*}{.03} & \multirow[t]{5}{*}{.01} \\
\hline Daily & 0.3 & 0 & & 0 & 0 & & \\
\hline $\begin{array}{l}\text { Several times a } \\
\text { week }\end{array}$ & 6.5 & 7.4 & & 4.2 & 5.4 & & \\
\hline Less often & 77.0 & 80.6 & & 80.6 & 81.5 & & \\
\hline Never & 8.6 & 10.9 & & 15.2 & 11.1 & & \\
\hline \multicolumn{8}{|l|}{ Cola, Lemonade } \\
\hline Several time a day & 3.4 & 2.4 & \multirow[t]{5}{*}{.26} & 3.4 & 3.0 & \multirow[t]{5}{*}{.09} & \multirow[t]{5}{*}{.05} \\
\hline Daily & 11.7 & 9.0 & & 10.4 & 12.4 & & \\
\hline $\begin{array}{l}\text { Several times a } \\
\text { week }\end{array}$ & 16.2 & 17.5 & & 15.1 & 10.4 & & \\
\hline Less often & 44.8 & 42.4 & & 41.6 & 44.3 & & \\
\hline Never & 22.3 & 26.3 & & 28.9 & 27.2 & & \\
\hline
\end{tabular}

NOTE: $p$ values of $<.05$ are significant. 
TABLE 3

Changes in Eating Attitudes Between Participants in the Intervention and Control Group (Baseline vs. Follow-Up)

\begin{tabular}{|c|c|c|c|c|c|c|c|}
\hline $\begin{array}{l}\text { What do You Want to } \\
\text { Change?. . }\end{array}$ & $\begin{array}{c}\% \text { at Baseline, } \\
\mathrm{M} \text { (SD), } \\
\text { Intervention } \\
\text { Group }\end{array}$ & $\begin{array}{c}\% \text { at Follow- } U p, \\
\text { M (SD), } \\
\text { Intervention } \\
\text { Group }\end{array}$ & $\mathrm{p}$ & $\begin{array}{l}\% \text { at Baseline, } \\
\text { M (SD), } \\
\text { Control Group }\end{array}$ & $\begin{array}{c}\% \text { at } \\
\text { Follow-up } \mathrm{M} \\
\text { (SD), Control } \\
\text { Group }\end{array}$ & $\mathrm{p}$ & $\begin{array}{c}\text { Interaction } \\
\text { (Group } \times \\
\text { Time) }\end{array}$ \\
\hline 1. Eating less & $2.64(1.40)$ & $2.78(1.47)$ & .06 & $2.80(1.49)$ & $2.94(1.31)$ & .16 & .85 \\
\hline 2. Eating more regularly & $3.82(1.21)$ & $3.77(1.26)$ & .41 & $3.81(1.29)$ & $3.76(1.21)$ & .58 & .35 \\
\hline $\begin{array}{l}\text { 3. Eating less snacks } \\
\text { between meals }\end{array}$ & $3.16(1.41)$ & $3.25(1.41)$ & .16 & $3.01(1.49)$ & $3.12(1.39)$ & .32 & .59 \\
\hline $\begin{array}{l}\text { 4. Taking more time for } \\
\text { my meals }\end{array}$ & $3.76(1.33)$ & $4.02(1.09)$ & .01 & $3.85(1.31)$ & $3.87(1.21)$ & .58 & .03 \\
\hline 5. Eating healthier & $3.91(1.09)$ & $3.85(1.08)$ & .53 & $3.82(1.10)$ & $3.67(1.08)$ & .33 & .29 \\
\hline 6. Lose weight & $3.34(1.62)$ & $3.35(1.58)$ & .77 & $3.35(1.59)$ & $3.46(1.44)$ & .32 & .43 \\
\hline
\end{tabular}

NOTE: $p$ values of <.05 are significant. $\mathrm{M}=$ median; $\mathrm{SD}=$ standard deviation.

TABLE 4

Percentage of Participants in Stages of Change Model From Baseline to Follow-up, by Eating Behavior

\begin{tabular}{|c|c|c|c|c|c|}
\hline \multirow[b]{2}{*}{ Participants } & \multicolumn{5}{|c|}{ Stage of Change, \% } \\
\hline & Precontemplation & Contemplation & Preparation & $\begin{array}{c}\text { Action/ } \\
\text { Maintenance }\end{array}$ & $\mathrm{p}$ \\
\hline \multicolumn{6}{|c|}{ Intervention group } \\
\hline Baseline & 29.7 & 30.2 & 27.6 & 7.4 & .001 \\
\hline Follow-up & 28.6 & 15.4 & 41.1 & 13.3 & \\
\hline \multicolumn{6}{|l|}{ Control group } \\
\hline Baseline & 35.6 & 29.9 & 24.2 & 6.0 & .001 \\
\hline Follow-up & 32.2 & 15.8 & 41.3 & 7.4 & \\
\hline \multicolumn{6}{|c|}{ Gender differences } \\
\hline \multicolumn{6}{|c|}{ Female } \\
\hline Baseline & 29.2 & 33.3 & 25.6 & 7.5 & .001 \\
\hline Follow-up & 28.1 & 14.2 & 43.8 & 14.3 & \\
\hline \multicolumn{6}{|l|}{ Male } \\
\hline Baseline & 30.4 & 28.2 & 29.3 & 8.1 & .001 \\
\hline Follow-up & 32.5 & 18.4 & 38.6 & 11.3 & \\
\hline
\end{tabular}

NOTE: $p$ values of $<.05$ are significant. Amounts of missing values are not described, and thus percentages across columns do not add up to $100 \%$.

multicomponent intervention were educational nutrition training in combination with physical exercise training during working hours. Despite 12 months of intervention, a satisfying adherence was obtained with a normal dropout after 12 months (8\%) and a high participation rate in the intervention group (50\%). In summary, positive effects on dietary behavior, intake, and readiness for change have been illustrated 12 months after the beginning of the intervention. Among the 890 participants in the beginning of the worksite health promotion, over $40 \%$ were overweight or obese, demonstrating how strongly health promotion programs at the workplace were relevant and required these days. 
We expected a significant weight loss after 12-month worksite health promotion. However, the results showed a nonsignificant weight loss trend. Although body weight did not decrease significantly in the intervention group, $7 \%$ of the participating workers experienced clinically significant weight loss of greater than $5 \%$ of baseline weight. Other workplace health promotion studies aiming at weight loss with intervention periods from 2 to 12 months have shown weight losses from 0.5 to $4.0 \mathrm{~kg}$ (Anderson et al., 2009; Christensen et al., 2011; Franz et al., 2007). Our study result showed a $0.5 \mathrm{~kg}$ weight loss, which means that in comparison to studies targeting similar participants or using comparable intervention methods, our study shows similar results (Brehm, Gates, Singler, Succop, \& D'Alessio, 2011; Kwak, Kremers, Visscher, van Baak, \& Brug, 2009).

It was found that eating behaviors and dietary intake, but not attitudes, in the intervention group improved more than in the comparison group. Positive food consumption changes were evident even among those who did not lose a significant amount of weight. The findings are consistent with other worksite health promotion programs that reported increased fruit and vegetable intake and decreased fast-food consumption among program participants. For example, the Treatwell 5-A-Day worksite study reported increased fruit and vegetable consumption among participants (Hunt et al., 2000). The study by Alinia et al. (2011) illustrated that it is possible to increase the average fruit and vegetable intake by simply increasing their availability and accessibility at work.

Likewise, free fruit was offered to this study's participants at the workplace in order to enhance fruit and vegetable intake. In addition, the trainer offered cooking lessons to show how easily healthy food can be prepared. Other interventions also reported significant effects on fruit intake as result of offering free fruit (Krogholm et al., 2010; Ohri-Vachaspati, Turner, \& Chaloupka, 2012).

As we hypothesized, workers' readiness to change their eating behavior demonstrated an improvement over time. In the intervention group, the participants' stage advanced, and $13 \%$ of the participants were in the action/maintenance stage at the end of the health program. Our results indicated that a workplace health promotion program including exercise and diet interventions may encourage behavioral eating changes in the participants. Likewise, other studies including behavioral components in health interventions also illustrated significant improvements (Kwak et al., 2009; Proper, Hildebrandt, Van der Beek, Twisk, \& Van Mechelen, 2003; Quintiliani, Poulsen, \& Sorensen, 2010; Rongen, Robroek, van Lenthe, \& Burdorf, 2013).
A study by Dutton, Napolitano, Whiteley, and Marcus (2008) underlines that physical training is an irreplaceable precondition in increasing motivation and action to change diet behavior.

As illustrated in the results section, participants in the intervention group did not show significant differences for every outcome variables (e.g., eating attitudes) compared to the comparison group; multifaceted interpretations are thus plausible. Reasons for this might be that the measurement of the determinants was not sufficiently sensitive to distinguish significant changes. It is also conceivable that the baseline assessment triggered participants in the comparison group to change their lifestyles and this may have affected the results. For example, participants in the comparison group also improved in several eating behavior outcomes (e.g., in terms of diet behavior) similar to the intervention group.

The timing of the assessments could also be relevant to explain the absence of significant effects. Other studies assessing the effectiveness of worksite health programs found main effects directly after the end of the intervention program (including an immediate follow-up measurement; Maes et al., 2012; Verweij et al., 2011). It is reasonable to assume that the reduced effects of our intervention wore off before the followup measurement. Similarly, several authors (e.g., Tapper, Pothos, Fadardi, \& Ziori, 2008) illustrated reduced effects at the follow-up measurement at 3 or 6 months.

\section{Strengths and Limitations of This Study}

This study examines the effectiveness of a worksite intervention targeting eating behaviors, eating attitudes, weight loss, and readiness to change in a quasi-experimental comparison group study design. The number of participants is quite large compared to other evaluation studies on the effectiveness of worksite interventions (Maes et al., 2012; Stephens, Cobiac, \& Veerman, 2014). In addition, the length of the intervention was 12 months. Another strength is that the intervention was designed for this target worker population.

Even with these study strengths, our investigation does have some limitations. First, this study was not randomized; the group was self-selected, which may limit the generalizability of results on program effectiveness. This evaluation study is further limited by the nature of the data, which were self-reported.

However, with having 12 months between baseline and follow-up, the self-report bias may have been minimized since participating workers can be assumed 
to not being able to remember the questions and responses of the baseline questionnaire.

To the extent that workers in the matched sample were different from workers for whom no data match was possible, the capability to generalize our results to participants of the overall program is limited.

\section{Conclusion}

The present research contributes to the literature on the effectiveness of worksite health promotion programs. The combination of nutrition interventions and physical exercise resulted in changes in eating behavior, dietary intake, and readiness to change dietary behavior after 12 months.

In summary, our findings from the 12-month pilot study suggest that a worksite health promotion program may improve nutritional health behaviors of workers. The positive results are encouraging regarding the use of workplace initiated weight loss interventions. However, the long-term effects (e.g., after 24 months) of this combined intervention remain to be investigated.

In addition, our study highlights the need for worksite health promotion strategies that provide increased motivation, support, and skills to enable employees living their life in a healthy way.

\section{REFERENCES}

Alinia, S., Lassen, A. D., Krogholm, K. S., Christensen, T., Hels, O. H., \& Tetens, I. (2011). A workplace feasibility study of the effect of a minimal fruit intervention on fruit intake. Public Health Nutrition, 14, 1382-1387.

Anderson, L. M., Quinn, T. A., Glanz, K., Ramirez, G., Kahwati, L. C., \& Johnson, D. B. (2009). The effectiveness of worksite nutrition and physical activity interventions for controlling employee overweight and obesity: A systematic review. American Journal of Preventive Medicine, 37, 340-357.

Bandura, A. (1963). Social learning and personality development. New York, NY: Holt, Rinehart \& Winston.

Berghoefer, A., Pischon, T., \& Reinhold, E. (2008). Obesity prevalence from a European perspective: A systematic review. $B M C$ Public Health, 8, 200.

Brehm, B. J., Gates, D. M., Singler, M., Succop, P. A., \& D’Alessio, D. A. (2011). Environmental changes to control obesity: A randomized controlled trial in manufactering companies. American Journal of Health Promotion, 25, 334-340.

Chapman, L. S. (2003). Meta-evaluation of worksite health promotion economic return studies. The Art of Health Promotion, 6(6), 1-10.

Christensen, J. R., Faber, A., Ekner, D., Overgaard, K., Holtermann, A., \& Sogaard, K. (2011). Diet, physical exercise and cognitive behavioral training as a combined workplace based intervention to reduce body weight and increase physical capacity in health care workers: A randomized controlled trial. BMC Public Health, 11, 671.

Deusinger, S. S. (2012). Exercise intervention for management of obesity. Pediatrics Blood \& Cancer, 58, 135-139.
Diehl, J. M., \& Staufenbiel, T. (1999). Inventar zum Essverhalten und Gewichtsproblemen IEG [Eating Disorder Inventory and Weight Problems (IEG)]. Eschborn, Germany: Klotz.

Dlugosch, G. E. (1992). Gesundheitsberatung [Health counseling]. In P. Schwenkmezger \& L. R. Schmidt (Eds.), Lehrbuch der Gesundheitspsychologie [Health psychology: a textbook] (pp. 222-233). Stuttgart, Germany: Enke.

Dutton, G. R., Napolitano, M. A., Whiteley, J. A., \& Marcus, B. H. (2008). Is physical activity a gateway behavior for diet? Findings from a physical activity trial. Preventive Medicine, 46, 216-221.

Franz, M. J., VanWormer, J. J., Crain, A. L., Boucher, J. L., Histon, T., Caplan, W., . . . Pronk, N. P. (2007). Weight-loss outcomes: A systematic review and meta-analysis of weight-loss clinical trials with a minimum 1-year follow-up. Journal of American Dietetic Association, 107, 1755-1767.

Graf, C., Ferrari, N., \& Eiser, S. (2013). Obesity-Status quo and therapeutic approaches. MMW Fortschritte der Medizin, 155(1), 91-94.

Hunt, M. K., Lederman, R., Stoddard, A., Potter, S., Phillips, J., \& Sorensen, G. (2000). Process tracking results from the Treatwell 5-A-Day worksite study. American Journal of Health Promotion, 14, 179-187.

Hutchinson, A. D., \& Wilson, C. (2011). Improving nutrition and physical activity in the workplace: A meta-analysis of intervention studies. Health Promotion International, 27, 238-249.

Jacobson, M. I., Yenney, S. L., \& Bisgard, J. C. (1990). An organizational perspective on worksite health promotion. Occupational Medicine, 5, 653-664.

Jensen, J. D. (2011). Can worksite nutritional interventions improve productivity and firm profitability? A literature review. Perspectives in Public Health, 131, 184-192.

Krogholm, K. S., Bredsdorff, L., Alinia, S., Christensen, T., Rasmussen, S. E., \& Dragsted, L. O. (2010). Free fruit at workplace intervention increases total fruit intake: A validation study using 24h dietary recall and urinary flavonoid excretion. European Journal of Clinical Nutrition, 64, 1222-1228.

Kuoppala, J., Lamminpaa, A., \& Husman, P. (2008). Work health promotion, job well-being, and sickness absences: A systematic review and meta-analysis. Journal of Occupational and Environmental Medicine, 50, 1216-1227.

Kwak, L., Kremers, S. P., Visscher, T. L., van Baak, M. A., \& Brug, J. (2009). Behavioral and cognitive effects of a worksite-based weight gain prevention program: The NHF-NRG in balance-project. Journal of Occupational and Environmental Medicine, 51, 1437-1446.

Maes, L., Van Cauwenberghe, E., Van Lippevelde, W., Spittaels, H., De Pauw, E., Oppert, J. M., \& De Bourdeaudhuij, I. (2012). Effectiveness of workplace interventions in Europe promoting healthy eating: A systematic review. European Journal of Public Health, 22, 677-683.

Matson-Koffman, D. M., Brownstein, J. N., Neiner, J. A., \& Greaney, M. L. (2005). A site-specific literature review of policy and environmental interventions that promote physical activity and nutrition for cardiovascular health: What works? American Journal of Health Promotion, 19, 167-193. 
Mensink, G. B. M., Schienkiewitz, A., Haftenberger, M., Lampert, T., Ziese, T., \& Scheidt-Nave, C. (2013). Overweight and obesity in Germany: Results of the German Health Interview and Examination Survey for Adults (DEGS1). Bundesgesundheitsbl, 56, 786-794.

Odeen, M., Magnussen, L. H., Maeland, S., Larun, L., Eriksen, H. R., \& Tveito, T. H. (2013). Systematic review of active workplace interventions to reduce sickness absence. Occupational Medicine, 63(1), 7-16.

Ohri-Vachaspati, P., Turner, L., \& Chaloupka, F. J. (2012). Fresh fruit and vegetable program participation in elementary schools in the United States and availability of fruits and vegetables in school lunch meals. Journal of the Academy of Nutrition and Dietetics, 112, 921-926.

Prochaska, J. O., \& Marcus, B. H. (1994). The transtheoretical model: Applications to exercise. In R. K. Dishman (Ed.), Advances in exercise adherence (pp. 161-180). Champaign, IL: Human Kinetics.

Prochaska, J. O., \& Velicer, W. F. (1997). The transtheoretical model of health behavior change. American Journal of Health Promotion, 2(1), 38-48.

Prochaska, J. O., Velicer, W. F., Redding, C. A., Rossi, J. S., Goldstein, M., \& DePue, J. (2005). Stage-based expert systems to guide a population of primary care patients to quit smoking, eat healthier, prevent skin cancer and receive regular mammograms. Preventive Medicine, 41, 406-416.

Proper, K. I., Hildebrandt, V. H., Van der Beek, A. J., Twisk, J. W., \& Van Mechelen, W. (2003). Effect of individual counseling on physical activity fitness and health: A randomized controlled trial in a workplace setting. American Journal of Preventive Medicine, 24, 218-226.

Quintiliani, L., Poulsen, S., \& Sorensen, G. (2010). Healthy eating strategies in the workplace. International Journal of Workplace Health Management, 3, 182-196.
Rongen, A., Robroek, S. J., van Lenthe, F. J., \& Burdorf, A. (2013). Workplace health promotion: A meta-analysis of effectiveness. American Journal of Preventive Medicine, 44, 406-415.

Schröer, S., Haupt, J., \& Pieper, C. (2014). Evidence-based lifestyle interventions in the workplace: An overview. Occupational Medicine, 64(1), 8-12.

Stephens, S. K., Cobiac, L. J., \& Veerman, J. L. (2014). Improving diet and physical activity to reduce population prevalence of overweight and obesity: An overview of current evidence. Preventive Medicine, 62(1), 167-178.

Stokols, D. (1992). Establishing and maintaining healthy environments: Toward a social ecology of health promotion. American Psychologist, 47, 6-22.

Tapper, K., Pothos, E. M., Fadardi, J. S., \& Ziori, E. (2008). Restraint, disinhibition and food-related processing bias. Appetite, 51, 335-338.

van Dongen, J. M., Proper, K. I., van Wier, M. F., van der Beek, A. J., Bongers, P. M., van Mechelen, W., \& van Tulder, M. W. (2012). A systematic review of the cost-effectiveness of worksite physical activity and/or nutrition programs. Scandinavian Journal of Work, Environment \& Health, 38, 393-408.

Van Duijvenbode, D. C., Hoozemans, M. J. M., Van Poppel, M. N. M., \& Proper, K. I. (2009). The relationship between overweight and obesity, and sick leave: A systematic review. International Journal of Obesity, 33, 807-816.

Verweij, L. M., Coffeng, J., van Mechelen, W., \& Proper, K. I. (2011). Meta-analyses of workplace physical activity and dietary behaviour interventions on weight outcomes. Obesity Reviews, 12, 406-429.

Vuillemin, A., Rostami, C., Maes, L., Van Cauwenberghe, E., Van Lenthe, F. J., Brug, J., \& Oppert, J. M. (2011). Worksite physical activity interventions and obesity: A review of European studies (the HOPE project). Obesity Facts, 4, 479-488. 